\title{
Temporal variation in soil resistance to flowing water erosion for soil incorporated with plant litters in the Loess Plateau of China
}

\author{
Long Sun ${ }^{\mathrm{a}, \mathrm{b}}$, Guang-hui Zhang ${ }^{\mathrm{a}, \mathrm{c}, *}$, Li-li Luan ${ }^{\mathrm{c}}$, Fa Liu ${ }^{\mathrm{c}}$

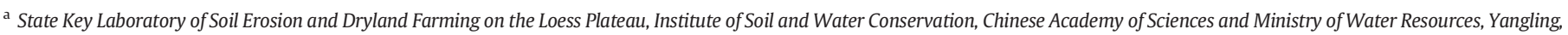 \\ Shaanxi 712100, China \\ b State Key Laboratory of Urban and Regional Ecology, Research Center for Eco-Environmental Sciences, Chinese Academy of Sciences, Beijing 100085, China \\ c School of Geography, Beijing Normal University, Beijing 100875, China
}

\section{A R T I C L E I N F O}

\section{Article history:}

Received 17 December 2015

Received in revised form 30 May 2016

Accepted 12 June 2016

Available online 16 June 2016

\section{Keywords:}

Soil detachment process

Rill erodibility

Critical shear stress

Litter decomposition

Flume experiment

\begin{abstract}
A B S T R A C T
Plant litter can be incorporated into topsoil under natural circumstances by soil splash, sediment deposition, and soil-dwelling animal activities. The incorporated litter can change the mechanical properties of soil and the decomposition of the incorporated litter can improve soil structural stability. Those changes likely influence soil detachment process by overland flow. This study was undertaken to quantify the effects of incorporated plant litters into topsoil on the temporal variation in soil resistance to detachment by overland flow using natural soil samples collected from four different plots (one control and three litter incorporation treatments) and then scoured under six different flow shear stresses in a hydraulic flume. The experiment started from April 19 to October 5, 2015 for 10 times at approximately 20 days sampling intervals. Soil properties and environmental parameters were also measured at each sampling time to explain the temporal variations in rill erodibility and critical shear stress. The results showed that the incorporated plant litter was effective to enhance soil resistance to flowing water erosion. Compared to bare soil, rill erodibilities of litter incorporated soils of black locust, sea buckthorn, and green bristle grass decreased by $24.3 \%, 33.5 \%$, and $34.8 \%$. The temporal variations in rill erodibility of bare and litter incorporated soils were similar. Rill erodibility decreased significantly over time as an exponential function for both bare and litter incorporated soils. The relative rill erodibility of three litter incorporated soils increased over time as a power function. The fitted critical shear stress increased exponentially over time. The temporal variations in rill erodibility could be explained by the temporal variations in soil consolidation, water stable aggregate, and litter decomposition. Rill erodibility could be well estimated by soil bulk density, water stable aggregate, and litter mass density $\left(r^{2}=0.92\right)$.
\end{abstract}

(c) 2016 Elsevier B.V. All rights reserved.

\section{Introduction}

Soil erosion involves the processes of soil detachment, sediment transport, and deposition. Soil detachment, defined as the soil particles being separated from the soil matrix at a particular location on the soil surface by erosive agents (Zhang et al., 2003), determines the amount of sediment that is potentially transferred to water bodies ( $\mathrm{Li}$ et al., 2015c). Soil detachment capacity $\left(D_{c}\right)$ and soil resistance to flowing water erosion (reflected by rill erodibility $\left(K_{r}\right)$ and critical shear stress $\left(\tau_{c}\right)$ ) are important input parameters for many process-based soil erosion models, such as the Water Erosion Prediction Project (WEPP) model (Nearing et al., 1989). Soil detachment process by overland flow is susceptible to soil physical properties (e.g. soil texture, bulk

\footnotetext{
* Corresponding author at: State Key Laboratory of Soil Erosion and Dryland Farming on the Loess Plateau, Institute of Soil and Water Conservation, Chinese Academy of Sciences and Ministry of Water Resources, Yangling, Shaanxi 712100, China.

E-mail address: ghzhang@bnu.edu.cn (G. Zhang).
}

density, water stable aggregate, soil cohesion) and the plant materials incorporated into topsoil, such as plant roots, crop residue, and plant litter (Brown et al., 1989; Knapen et al., 2007a; Li et al., 2015a; Wang et al., 2014; Zhang et al., 2014).

As an important component of near soil surface characteristics, apart from covering on soil surface, plant litter usually can be incorporated into topsoil under natural circumstance through three different approaches: soil splash, sediment deposition and soil animal activities (Geddes and Dunkerley, 1999; Laossi et al., 2010; Tsukamoto, 1991; Wilson et al., 2008). Soil particles are splashed by raindrops wrapping litter up by adhesive force and lead to a large amount of plant litter coated with soil particles after rainfall. Plant litter and detached soil particles can be transported downslope and deposited together in low areas (Tsukamoto, 1991). The deposited litter can form mini-dam in rills, which traps and deposits sediment to facilitate the mixture (Pannkuk and Robichaud, 2003; Wilson et al., 2008). Plant litter can also be partly translocated to topsoil by soil animals, like earthworms and soil-dwelling insects (Laossi et al., 2010; Ma et al., 2014). 
Generally, plant litter can be incorporated into topsoil before fully fragmented (Tsukamoto, 1991; Li et al., 2015a). The incorporated rate changes with climatic conditions and vegetation communities. Tsukamoto (1991) reported that the rates of plant litter incorporated into topsoil $(0-5 \mathrm{~cm})$ caused by sediment deposition ranged from 0.10 to $0.28 \mathrm{~kg} \mathrm{~m}^{-2}$ in the Japanese cypress stands. Li et al. (2015a) found that the incorporating rates of plant litter into $0-5 \mathrm{~cm}$ topsoil varied from 0.07 to $1.08 \mathrm{~kg} \mathrm{~m}^{-2}$ with a mean of $0.32 \mathrm{~kg} \mathrm{~m}^{-2}$ at a $90 \mathrm{~m}$ long and $40 \mathrm{~m}$ wide ephemeral gully developed hillslope covered with black locust (Robinia pseudoacacia L.) in Zhifanggou small watershed of the Loess Plateau.

The incorporated plant litter can influence soil properties related to soil detachment by overland flow such as increase in soil aggregate stability, soil organic matter, and decrease in soil bulk density (Kladivko and Unger, 1994; Mandal et al., 2004). Similar to the effect of buried crop residue in situ by conservation field management on soil properties, the incorporated litter can change soil structural stability thus modify soil resistance to detachment by overland flow. More importantly, the incorporated litter also affects soil properties greatly by releasing fragmented organic substance to soil mass through mineralization and humification processes (Durán et al., 2004; Ma et al., 2014). Morachan et al. (1972) found that the size of wet aggregate increased progressively with increased residue addition. Black (1973) reported a significant increase in soil aggregate and a significant decrease in bulk density with increasing incorporated residue levels. Bhagat and Verma (1991) conducted a field experiment for 5 years and proved that water stable aggregates and soil bulk density under litter incorporation treatment were significantly higher and lower than those of control. Some other studies (Ghuman and Sur, 2001; Kladivko and Unger, 1994) also observed a distinguishable decrease in soil bulk density after litter incorporation.

The effects of incorporated litter on soil properties change with time. Immediately after incorporation, the mechanical effect of litter on enhancing soil stability is at its maximum. Then, the litter decomposes and its rate is controlled by soil temperature and moisture conditions (Brown et al., 1989). After a period of decomposition, the incorporated litter may still offer some mechanical resistance to flowing water erosion. But the interactive effects of the mechanical resistance and litter decomposition on soil properties may produce uncertain alteration in soil erosion (Brown et al., 1989; Franti, 1987; Knapen et al., 2007a). Brown et al. (1990) studied rill erosion after incorporation of crop residue and pointed out that natural soil consolidation over time likely masked the effect of residue incorporation on topsoil resistance. However, Zeleke et al. (2004) revealed that soil cohesion at the $5 \mathrm{~cm}$ depth reduced compared to control after three (annual) residue incorporations. Therefore, it is essential to investigate the temporal variation in the effects of incorporated litter on soil properties and soil detachment by overland flow under different conditions.

Soil detachment process by overland flow (or rill erosion) is affected considerable by the plant litter incorporation. Van Liew and Saxton (1983) found that residue incorporation could significanly increase soil resistance to flowing water erosion and reduce rill erosion rate. A recent study conducted by Knapen et al. (2007a) demonstrated that the decomposition of incorporated residue could enhance the stability of topsoil, which was closely related to the litter biomass loss by decomposition. But the correlation was weak and thus more additional experiments under controlled conditions were required to define the exact relationships between incorporated plant materials and soil resistance to flowing water erosion. A more recent study was carried out by Li et al. (2015a) at a hillslope covered with approximately 20-year black locust (Robinia pseudoacacia L.) in the Loess Plateau. Their results revealed that the mass density of incorporated litter had significantly positive influence on reducing soil detachment capacity by overland flow for 0$5 \mathrm{~cm}$ topsoil. However, the temporal variation in the effects of incorporated litter decomposition on soil detachment process by overland flow is still unknown.
Great efforts have been paid to restore vegetation and reduce soil and water losses in the Loess Plateau of China (Chen et al., 2007). For example, the Grain for Green Project was implemented in 1999 in the Loess Plateau. As a result, $>2$ million ha of steep slope croplands have been converted to woodland or grassland in the past several years (Chang et al., 2011; Deng et al., 2014). A rapid accumulation of plant litter always occurs after the cropland is newly converted to woodland or grassland (Clark et al., 2001; Olson, 1963). It is supported by the facts of abundant plant litter accumulation following vegetation restoration in the Loess Plateau (An et al., 2013; Ma et al., 2014). Consequently, extensive undecomposed or partly decomposed plant litters are incorporated into topsoil in this region (Li et al., 2015a).

As mentioned above, the plant litter incorporated into topsoil and its decomposition over time likely have great influence on soil detachment process by overland flow and its temporal variation. Nevertheless, few studies have been conducted to investigate the potential effects of incorporated plant litter on the temporal variation in soil detachment by overland flow. Therefore, the objectives of this study were to quantify the temporal variations in soil resistance to flowing water erosion of topsoil incorporated with three different plant litters and to identify the factors influencing these variations in the Loess Plateau of China.

\section{Materials and methods}

\subsection{Study area and sampling site}

The experiments were performed at the Ansai field station $\left(109^{\circ} 18^{\prime}\right.$ $51^{\prime \prime} \mathrm{E}, 36^{\circ} 51^{\prime} 15^{\prime \prime} \mathrm{N}$ ) of the Institute of Soil and Water Conservation, Chinese Academy of Sciences. It is located in a typical loess-hilly region with a typical silt loam loess-derived soil. The climate is a semi-arid, continental with a mean annual temperature of $8.8^{\circ} \mathrm{C}$ and precipitation of $505 \mathrm{~mm}>70 \%$ of precipitation falls during June to September (summer months) as heavy storms with short duration. The principal land uses are cropland, orchard, shrub land, woodland, grassland, and wasteland. The major vegetation species are Robinia pseudoacacia Linn., Pinus tabulaeformis Carr., Hippophae rhamnoides Linn., Caragana korshinskii, Astragalus adsurgens, and Artemisia capillaries.

The sampling field is a 21 year-old man-made level terrace and the elevation is $1290 \mathrm{~m}$. It was fallowed for one year before the experiment was performed. The soil is a typical silt loam with $12.6 \%$ clay, $60.6 \%$ silt, and $26.8 \%$ sand. The field was tilled twice with a rototiller (the tillage depth ranged from 25 to $34 \mathrm{~cm}$ ) to homogenize soil properties in early May 2014, and was left open to natural environmental conditions until November. Then the field was divided into 4 plots ( 3 for litter incorporation and 1 for control as baseline) with a length of $12 \mathrm{~m}$ and a width of $3 \mathrm{~m}$. Plant litters of Robinia pseudoacacia Linn. (Black locust, abbr. BL), Hippophae rhamnoides Linn. (Sea buckthorn, abbr. SB), and Setaria viridis (L.) Beauv. (Green bristle grass, abbr. GBG) were collected from a nearby small watershed (Zhifanggou). The litters of black locust and sea buckthorn were consisted of leaves and a few twigs with a mean length of approximately $3 \mathrm{~cm}$. But the litter of green bristle grass was mainly stalks and a few leaves and thus it was chopped to the same length with other two litters. Prior to incorporation, the plant litters were air-dried to constant mass. The plots were plowed again to incorporate plant litter into $0-5 \mathrm{~cm}$ topsoil layer with a rate of $0.35 \mathrm{~kg} \mathrm{~m}^{-2}$ for all three plant litters based on the field investigation in Zhifanggou small watershed by Li et al. (2015a). Then the plots were raked by hands to make a relatively smooth, uniform soil surface. All prepared plots were left free to open natural environmental conditions until April 2015.

\subsection{Soil sampling}

Undisturbed topsoil samples were collected from all four plots for 10 times during the whole experimental period, from April 19, 2015 to October 5, 2015 at approximately 20 days sampling intervals. For each 
plot, thirty samples were collected at each sampling time and altogether 1200 samples (30 samples per plot $\times 4$ plots $\times 10$ times of samplings) were collected. Soil sampling procedures described by Zhang et al. (2003) were utilized to collect samples for all plots. Soil samples were collected from topsoil using a circular steel ring with $10.0 \mathrm{~cm}$ in diameter and $5.0 \mathrm{~cm}$ in depth (Zhang et al., 2003, 2009). When sampling the steel ring was gradually pushed into soil, then excavated and cut carefully across the bottom rim of the sampler. Both ends of the ring were protected by cotton cloth cushion to prevent potential disturbances during transport (Zhang et al., 2003). Soil samples were weighed as soon as possible to prevent the influence of soil moisture on the initial soil mass of sample. The environmental parameters (i.e. precipitation and temperature) influencing litter decomposition were also observed during the experimental period (Fig. 1). In the whole experimental period, the total precipitation was $206.4 \mathrm{~mm}$ and the accumulated temperature (defined as the total degrees Celsius of the average daily temperatures exceed $10^{\circ} \mathrm{C}$ ) was $3827.5^{\circ} \mathrm{C}$.

Simultaneously, soil moisture, bulk density $(B D)$, soil cohesion $(S C)$, water stable aggregate (WSA), and the litter density $(L D)$ within topsoil were measured for four plots at each sampling time. Moisture and bulk density of the topsoil ( $5 \mathrm{~cm}$ ) were measured for 6 replicates using steel rings ( $5 \mathrm{~cm}$ in diameter and $5 \mathrm{~cm}$ in height) by oven-dried method. The mean soil water content was used to calculate the original dry mass of the soil sample. Soil cohesion was measured for 12 replicates by a pocket torvane (Durham Geo-enterprises, Inc., UK) at the saturated soil surface wetted by a light spraying (Zhang et al., 2009). Water stable aggregate was measured for triplicates by the wet-sieving method. The non-decomposed plant litter within soil sample was collected with the same circular steel ring by washing method over a sieve for 12 replicates per plot at each sampling time and oven-dried for $24 \mathrm{~h}$ at $65^{\circ} \mathrm{C}$. The dry plant litters were weighed and the mean was used to calculate the litter mass density for soil samples collected from that plot and sampling time.

\subsection{Experimental flume and hydraulic conditions}

In order to obtain the stable hydraulics of overland flow, a $4.0 \mathrm{~m}$ long, $0.35 \mathrm{~m}$ wide flume was used to measure soil detachment capacity in the current study. To simulate the hydraulic roughness of soil samples, soil collected from the field was air-dried, passed through $2 \mathrm{~mm}$ sieve, and then glued on the surface of the flume bed (Zhang et al., $2003,2009)$. The slope of the flume was adjusted by a pulley gear. Water was pumped to the flume and flow discharge was controlled by a series of valves. The maximum surface flow velocity was measured by the fluorescent dye technique with ten replications when the flow became stable. Then the mean maximum surface flow velocity was adjusted by a reduction coefficient of 0.8 to obtain the mean flow velocity (Luk and Merz, 1992). Flow depth was calculated as:

$$
h=\frac{Q}{B V}
$$

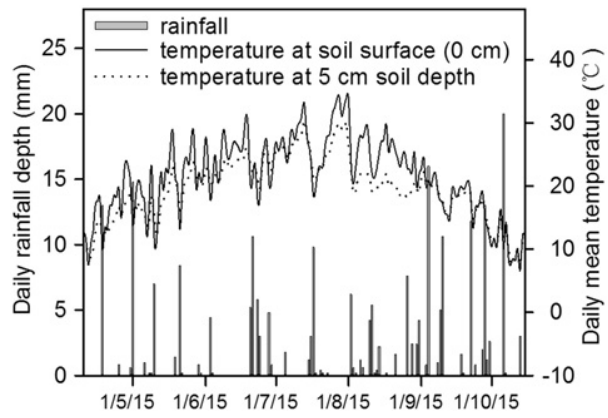

Fig. 1. Rainfall and soil temperature for the whole experimental period. where $h$ is the flow depth $(\mathrm{m}), Q$ is the flow discharge $\left(\mathrm{m}^{3} \mathrm{~s}^{-1}\right), B$ is the width of the flume $(\mathrm{m})$, and $v$ is the mean flow velocity $\left(\mathrm{m} \mathrm{s}^{-1}\right)$. The flow shear stress was calculated as (Zhang et al., 2003):

$\tau=\rho g H S$

where $\tau$ is the flow shear stress (Pa), $\rho$ is the water mass density $\left(\mathrm{kg} \mathrm{m}^{-3}\right), \mathrm{g}$ is the gravitational acceleration $\left(\mathrm{m} \mathrm{s}^{-2}\right), H$ is the flow depth $(\mathrm{m})$, and $S$ is the sine of flume bed slope $\left(\mathrm{m} \mathrm{m}^{-1}\right)$. In this study, six combinations of flow rates and slope gradients $\left(8.7 \% \& 0.51 \mathrm{~s}^{-1}\right.$, $8.7 \% \& 1.51 \mathrm{~s}^{-1}, 17.4 \% \& 1.01 \mathrm{~s}^{-1}, 17.4 \% \& 1.51 \mathrm{~s} \mathrm{~s}^{-1}, 17.4 \% \& 2.01 \mathrm{~s} \mathrm{~s}^{-1}$, and $17.4 \% \& 2.51 \mathrm{~s}^{-1}$ ) were applied to obtain six different flow shear stresses ranged from 5.27 to $17.70 \mathrm{~Pa}$.

\subsection{Soil detachment capacity measurement and soil erosion resistance estimation}

Prior to the test of soil detachment capacity, soil samples were saturated in a container for $8 \mathrm{~h}$ and drained for $12 \mathrm{~h}$. Then the soil sample was inserted into a hole ( $0.5 \mathrm{~m}$ above the lower end of flume) on the flume bed and was scoured by flowing water under designed flow shear stress (Zhang et al., 2003). The soil sample was detached to a similar souring depth $(2 \mathrm{~cm})$ to decrease the influence of uneven detachment within the sample (Nearing et al., 1991; Zhang et al., 2003). Then the scoured sample was oven dried at $105^{\circ} \mathrm{C}$ for $24 \mathrm{~h}$ and weighed to calculate the final dry soil mass. The plant litter washed away from the sample during the process of scouring was collected using fine mesh plastic nets at the flume outlet, and then was oven dried at $65^{\circ}$ $\mathrm{C}$ for $24 \mathrm{~h}$ and weighed. Soil detachment capacity $\left(D_{c}, \mathrm{~kg} \mathrm{~m}^{-2} \mathrm{~s}^{-1}\right)$ was calculated as (Zhang et al., 2003, 2009):

$D_{c}=\frac{M_{o}-M_{f}-M_{l}}{t A}$

where $M_{o}$ is the original dry mass of soil sample $(\mathrm{kg}), M_{f}$ is the final dry soil mass after scouring $(\mathrm{kg}), M_{l}$ is the dry mass of non-decomposed plant litter fragments washed away during the test $(\mathrm{kg}), A$ is the section-area of soil sample $\left(\mathrm{m}^{2}\right)$, and $t$ is the test duration ( $\left.\mathrm{s}\right)$. Soil detachment capacity was tested for five replicates under each flow shear stress and the mean was considered as the soil detachment capacity for that shear stress. A total of 1200 samples were scoured.

Rill erodibility is defined as the increase in soil detachment capacity per unit increase in flow shear stress. Critical shear stress is a threshold parameter defined as the value above which a rapid increase in soil detachment capacity per unit increase in shear stress occurs. In WEPP model (Nearing et al., 1989), soil resistance to detachment by overland flow was estimated as:

$D_{c}=K_{r}\left(\tau-\tau_{c}\right)$

where $K_{r}$ is the rill erodibility $\left(\mathrm{s} \mathrm{m}^{-1}\right)$, and $\tau_{c}$ is the critical shear stress (Pa).

When the measured detachment capacities were plotted against flow shear stresses, rill erodibility and critical shear stress could be estimated from the slope and $\mathrm{x}$-intercept of the linear regression line. Thus values of $K_{r}$ and $\tau_{c}$ were obtained for each plot of every sampling time. The temporal changes in rill erodibility for topsoil with incorporated litter were likely affected by the soil consolidation over time in the experimental period. To draw more general conclusions on erodibilitymodifying effect of litter incorporation on topsoil, rill erodibilities of litter incorporated plots were divided by $K_{r}$ of control plot (without incorporated litter), defined as the relative rill erodibility $\left(R K_{r}\right)$. The $R K_{r}$ thus corresponded to the relative modification in rill erodibility after litter incorporation compared with the $K_{r}$ for bare control (Knapen et al., 2008; Knapen et al., 2007b). 


\subsection{Statistical analysis}

The Kolmogorov-Smirnov (K-S) test was performed to determine the normality of the raw data (Wang et al., 2010; Li et al., 2015a). Differences in soil detachment capacity between different sampling times were detected using one-way analysis of variance (ANOVA). Paired $t$ test was used to detect the difference in soil detachment capacity, rill erodibility, and critical shear stress between control and litter incorporated plots, and also the differences in relative rill erodibility between different plant litter species (Zhang et al., 2009). The changing trend of rill erodibility over time, and relationships between rill erodibility, critical shear stress and their influencing factors were analyzed by the Pearson correlation and curve estimation methods (Li et al., 2015a). All statistical analyses were performed using IBM SPSS Statistics (Version 19.0, SPSS Inc., Chicago, IL).

\section{Results and discussion}

\subsection{Temporal variations in soil resistance to flowing water erosion}

The estimated rill erodibilities ranged from 0.22 to $0.35 \mathrm{~s} \mathrm{~m}^{-1}, 0.18$ to $0.27 \mathrm{~s} \mathrm{~m}^{-1}, 0.17$ to $0.24 \mathrm{~s} \mathrm{~m}^{-1}$, and 0.17 to $0.24 \mathrm{~s} \mathrm{~m}^{-1}$ for control, BL, $\mathrm{SB}$, and GBG treatments. The mean values were $0.27,0.22,0.20$, and $0.20 \mathrm{~s} \mathrm{~m}^{-1}$. The rill erodibilities estimated in this study are the same magnitude as the erodibilities range from 0.15 to $0.33 \mathrm{~s} \mathrm{~m}^{-1}$ reported by Li et al. (2015b), which were measured under different soil types and land uses in a nearby typical small watershed in the Loess Plateau. The measured results are also the same order of magnitude with those measured from typical croplands by Yu et al. (2014a) in the Loess Plateau. Paired-t-test showed that rill erodibilities differed significantly between most plots (BL and GBG: $p=0.005$; the other: $p<0.001$ ) except for SB and GBG $(p=0.616)$. Compared to control, the mean rill erodibilities of BL, SB, and GBG reduced by $24.3 \%, 33.5 \%$, and $34.8 \%$. This result indicated that the incorporated plant litter was effective to enhance soil resistance to flowing water erosion. The result also showed that the effects of litter incorporation in topsoil on rill erodibility were related to litter species. In this study, sea buckthorn and green bristle grass were more effective than black locust to prevent soil to be detached by overland flow. This difference was likely produced by the differences in litter mechanical properties and decomposition rate since the same litter rate was incorporated for three plant litter species.

The distinguishable temporal variations in measured rill erodibilities were found for both control and litter incorporated plots (Fig. 2a). For bare plot, $K_{r}$ decreased fast from the end of April to the end of August, and then declined slowly. For three litter incorporated plots, $K_{r}$ increased slightly from the end of April to the early of May. They decreased continually till the end of August and then fluctuated slightly. The simple regression found that rill erodibilities decreased exponentially over time for control $\left(r^{2}=0.96, p<0.001\right)$ and litter incorporated plots (BL: $r^{2}=0.97, p<0.001$; SB: $r^{2}=0.96, p<0.001$; GBG: $r^{2}=0.92$, $p<0.001$ ). This result proved the hypothesis of Brown et al. (1990) and Knapen et al. (2007a), who assumed that changes in $K_{r}$ was assumed to show a decreasing trend with time after disturbance or tillage. The decreasing trend in $K_{r}$ was caused by the temporal variations in soil properties and litter characteristics, which would be discussed latter.

To separate the effect of incorporated litter from soil properties, the temporal variation in relative rill erodibility was analyzed (Fig. 2b). It was obviously that temporal variation in $R K_{r}$ was similar for three different plant litter species. The relative rill erodibilities increased in the whole experimental period, though GBG had a great increase than other two treatments. This difference was likely caused by the difference in decomposition rates of different litter species. Simple regression showed that $R K_{r}$ of three litter species increased over time as a power function (BL: $r^{2}=0.46, p=0.031$; SB: $r^{2}=0.70, p=0.003$; GBG: $\left.r^{2}=0.87, p<0.001\right)$. This result demonstrated that the rill erodibilityreducing effect of the incorporated litter decreased over time due to (a)

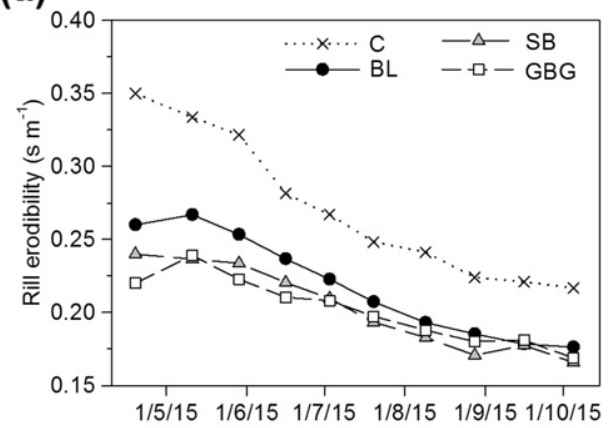

(b)

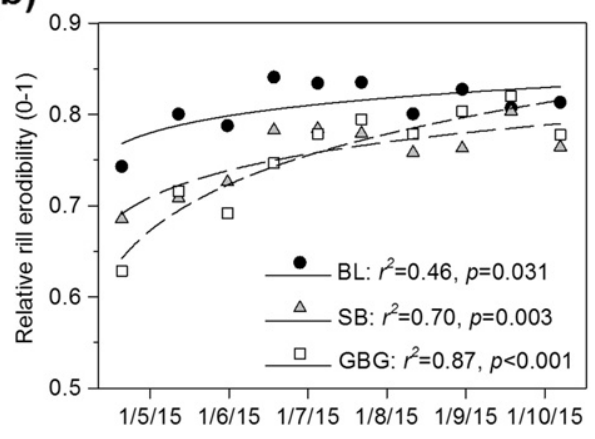

Fig. 2. Temporal variations in rill erodibility (a) and the relative rill erodibility.

the decomposition of litter and the mechanical effect of incorporated litter declined.

The fitted critical shear stresses varied from 4.09 to $4.38 \mathrm{~Pa}, 4.50$ to $4.78 \mathrm{~Pa}, 4.53$ to $4.92 \mathrm{~Pa}$, and 4.21 to $4.50 \mathrm{~Pa}$ for control, BL, SB, and GBG, respectively (Fig. 3). Compared to control, the mean critical shear stresses of BL, SB, and GBG increased by $9.4 \%, 10.9 \%$, and $2.2 \%$. This result indicated that litter incorporation into topsoil also had effects on critical shear stress. But they were relatively slight compared to the influences on rill erodibility.

The estimated critical shear stresses fluctuated in all cases (Fig. 3). For control, $\tau_{c}$ increased gradually from April to the end of May, and it decreased sharply to the minimum. It increased quickly again to the middle of July and then increased slowly till the end of measurement period. The seasonal variation in critical shear stress was similar for BL and SB treatments (Fig. 3). $\tau_{c}$ declined from April to the early of June, and then increased continually with distinguishable fluctuation. For GBG plot, the estimated critical shear stress decreased from April to the early of June and then it increased gradually till the end of measurement period (Fig. 3). Paired-t test showed that critical shear stresses differed significantly between most plots (GBG and Control: $p=0.007$, the others: $p<0.001)$ except for BL and SB $(p=0.125)$. The differences in temporal variations of critical shear stress between different treatments were also produced by the differences in soil properties and litter

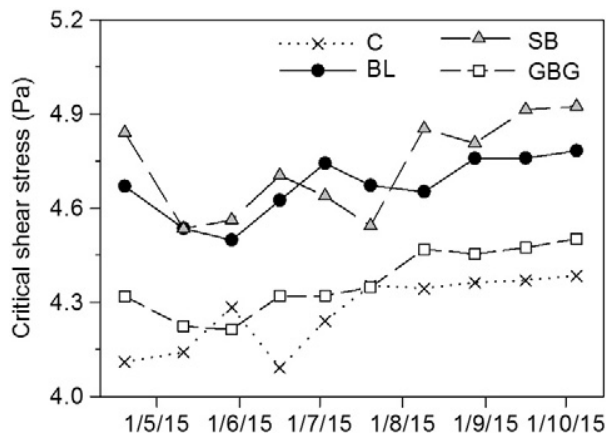

Fig. 3. Temporal variations in critical shear stress. 
characteristics over time, which would be discussed later. Compared to rill erodibility, the temporal variation in critical shear stress was relative small. This result is in accordance with the expectation of Knapen et al. (2007a).

\subsection{Factors influencing the temporal variations in rill erodibility}

\subsubsection{Soil consolidation}

The consolidation of the topsoil over time after disturbance (e.g. tillage) could be well reflected by the increase in soil bulk density and soil cohesion (Knapen et al., 2007a; Yu et al., 2014a; Zhang et al., 2009). As shown in Fig. 4a and b, both soil bulk density and soil cohesion demonstrated a clear increasing trend. This result revealed a distinguishable process of soil consolidation, which certainly led to the decrease trend in rill erodobility and the increase trend in critical shear stress as discussed above.

Similar with the findings of Mapa et al. (1986) and Knapen et al. (2007a), the increase in soil bulk density due to consolidation induced by raindrop impact and gravity followed an asymptotic trend. This change partially explained the asymptotic decrease in rill erodibility over time. Fig. 5a showed fairly good relationships between $K_{r}$ and soil bulk density of $0-5 \mathrm{~cm}$ topsoil for control and litter incorporated plots. The strong exponential relationship between rill erodibility and soil bulk density is consistent with the conclusions of the previous studies (Knapen et al., 2008; Yu et al., 2014a; Zhang et al., 2009).

As shown in Fig. 5b, rill erodibility decreased significantly with soil cohesion as an exponential function except for GBG treatment. The weak relationship between $K_{r}$ and SC for GBG was likely attributed to the litter composition (mainly consisted of stalks). The exponential relationship between rill erodibility and soil cohesion is consistent with the findings of previous studies (Li et al., 2015b; Mamo and Bubenzer, 2001; Yu et al., 2014a; Zhang et al., 2009).

\subsubsection{Water stable aggregate}

Water stable aggregate, reflecting the structural stability of soil, has often been used as an indicator of soil susceptibility to flowing water erosion (Barthes and Roose, 2002; Li et al., 2015a, 2015b, 2015c; Yu et al., 2014a). In this study, the measured water stable aggregates increased continually during the whole period of experiment (Fig. 4c) caused by the processes of aging and aggregation formation (Allison,
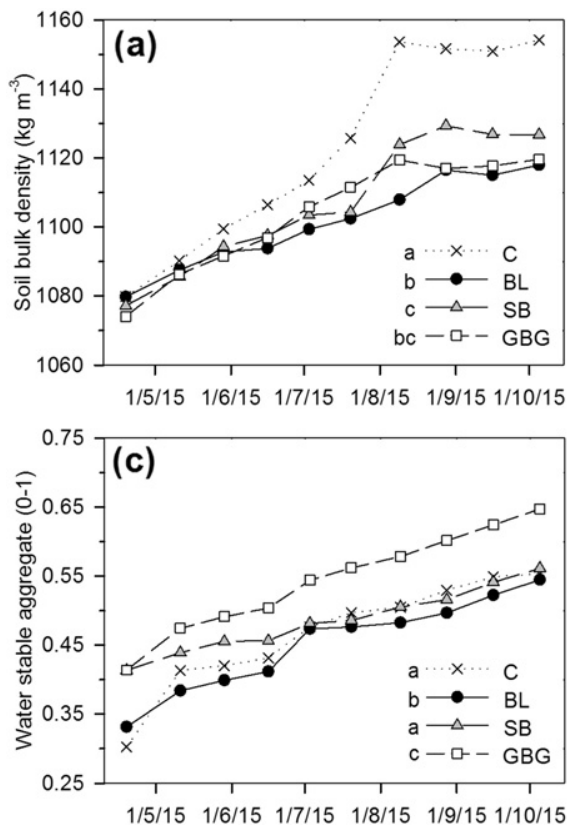

1968; Mandal et al., 2004). The temporal variation in water stable aggregates certainly had great effect on the temporal variation in rill erodibility since aggregates were more resistant to detachment by overland flow (Yu et al., 2014b). The water stable aggregates differed significantly between control and BL $(p=0.021)$, and control and GBG $(p<0.001)$. This result partially explained the roles of litter incorporation into topsoil to enhance soil resistance to flowing water erosion.

Rill erodibility decreased exponentially with water stable aggregate (Fig. 5c). Compared to control, rill erodibility of litter incorporated plots was obviously low when water stable aggregate was equal. This result indirectly implied the mechanical binding effects of litter incorporation on soil detachment process by overland flow. The difference in exponents of regression lines was likely derived from the plant litter species, including its substrate quality (e.g. content of $\mathrm{C}, \mathrm{N}$, lignin and cellulose in plant materials) and mechanical characteristics (e.g. shape and size, and structural stability determined by lignin and cellulose).

\subsubsection{Decomposition of incorporated litter}

The remaining litter mass in $0-5 \mathrm{~cm}$ topsoil decreased progressively due to litter decomposition (Fig. 4d) over time. The decomposition rates of different litter species were almost the same before the middle June. Then clear differences were demonstrated between three litter species. The litter of BL was decomposed fast than other two litter species. This difference was likely caused by the differences in substrate quality of litters and in micro environmental conditions between different plots (i.e. soil moisture and temperature). Further analysis showed that $R K_{r}$ decreased exponentially with the remaining litter mass density in $0-$ $5 \mathrm{~cm}$ topsoil (Fig. 5d).

\subsection{Factors affecting the temporal variation in critical shear stress}

Critical shear stress was pronounced correlated with soil bulk density for control $(R=0.86, p=0.001), \mathrm{BL}(R=0.69, p=0.026)$, and GBG $(R=0.81, p=0.005)$, but not for SB $(R=0.59, p=0.073)$. Soil cohesion has been considered as the best soil property to estimate critical shear stress (Léonard and Richard, 2004). It was partially confirmed by the results of this study (Fig. 6a). The critical shear stress increased significantly with soil cohesion for control $\left(r^{2}=0.70, p=0.003\right)$ and SB treatments $\left(r^{2}=0.42, p=0.043\right)$. However, the relationships were weak between SC and critical shear stress for BL and BGB plots.
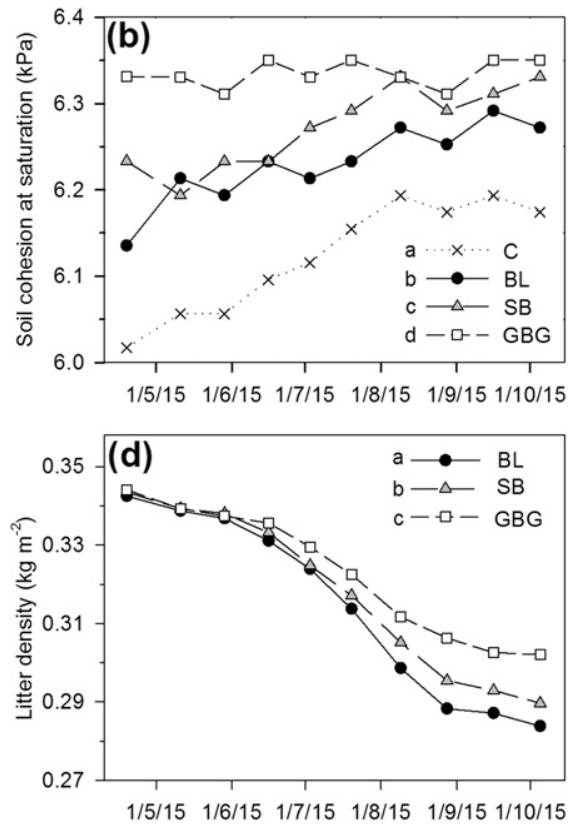

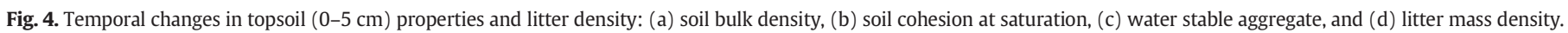
Different letters denote the significant differences at $p<0.05$. 


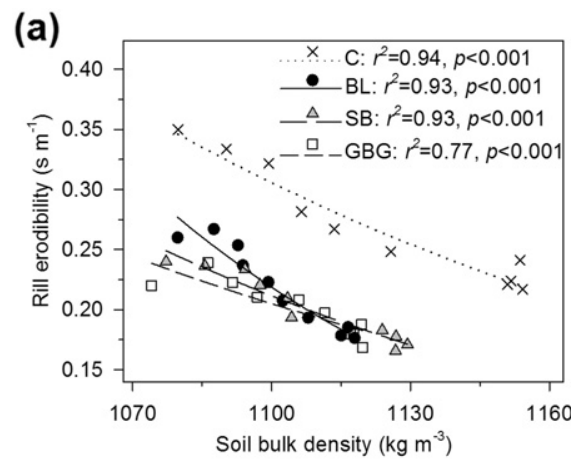

(c)

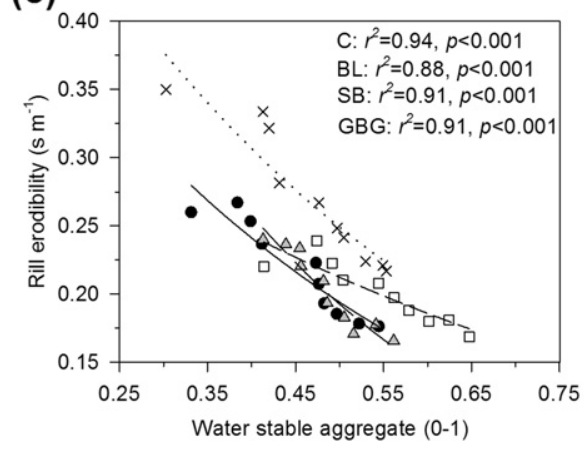

(b)

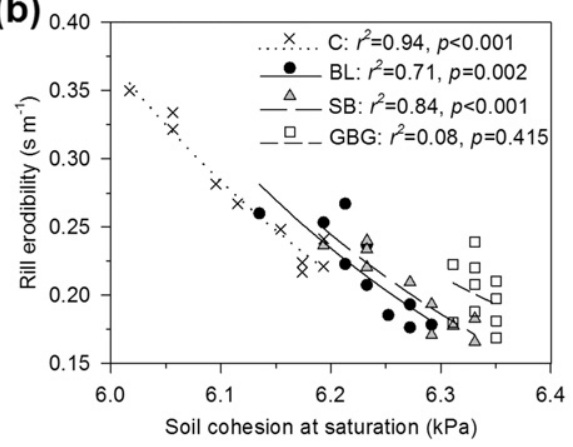

(d)

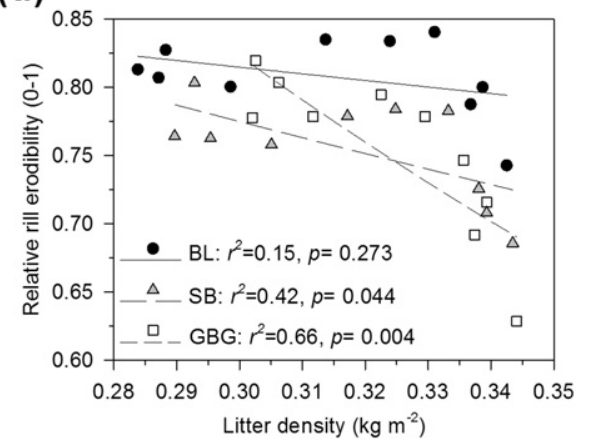

Fig. 5. Relationships between rill erodibility and soil bulk density (a), soil cohesion at saturation (b), water stable aggregate (c); and relative rill erodibility and litter density (d).

Critical shear stress was strongly correlated with water stable aggregate for control $(R=0.85, p=0.002)$, BL $(R=0.71, p=0.022)$, and GBG $(R=0.82, p=0.004)$ but not for $\mathrm{SB}(R=0.57, p=0.086)$. The fitted critical shear stress was significantly correlated to remaining litter mass density over time for all three litter incorporated plots (Fig. 6b).

(a)

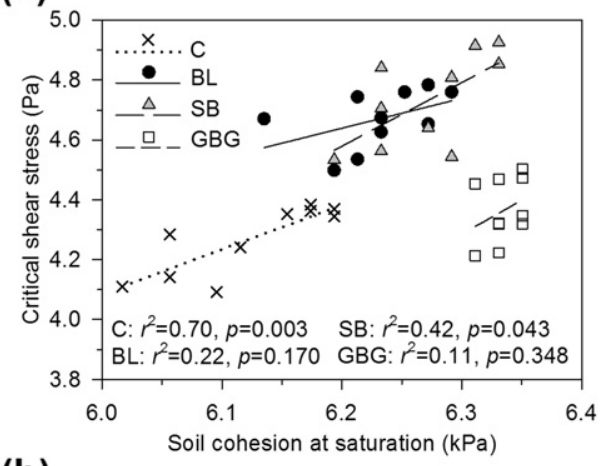

(b)

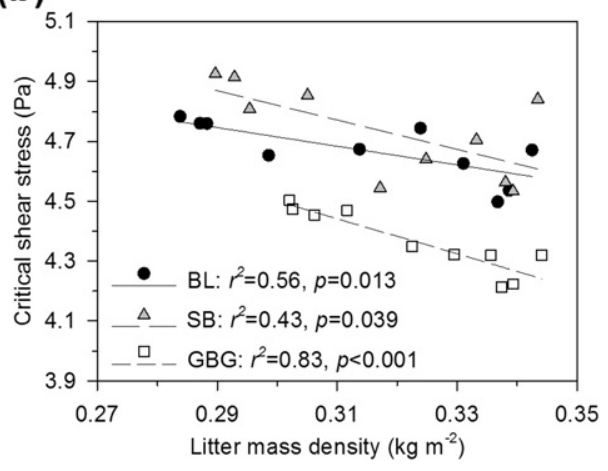

Fig. 6. Relationships between critical shear stress and soil cohesion at saturation (a), and litter density (b).
To analyze the relative effect of litter mass density on $\tau_{c}$, the critical shear stresses of BL, SB, and GBG were devided by $\tau_{c}$ of control (relative critical shear stress). The correlation analysis showed that no remarkable relationship existed between relative $\tau_{c}$ and litter mass density for any litter species. This result indicated that the incorporate litter had little effects on the temporal variation in critical shear stress and its seasonal change was mainly caused by the process of soil consolidation as discussed above. Hence, the critical shear stress was not estimated in the next section.

\subsection{Rill erodibility estimation}

Rill erodibility is difficult to be measured directly in both field and laboratory conditions. It is necessary to estimate $K_{r}$ using easily measured soil and plant properties. In this study, non-linear regression analysis showed that rill erodibility could be estimated well by soil bulk density $\left(\mathrm{kg} \mathrm{m}^{-3}\right)$, water stable aggregate (0-1), and litter mass density $\left(\mathrm{kg} \mathrm{m}^{-2}\right)$ :

$K_{r}=58.779 \mathrm{e}^{(-0.004 B D-0.880 W S A-0.953 L D)}, r^{2}=0.92, n=40$

In general, the estimated rill erodibilities matched the measured values well (Fig. 7). But obvious error still existed for some litter species, i.e. black locust. Further studies are necessary to further simulate the temporal variation in soil resistance to flowing water erosion caused by plant litter incorporation into topsoil under wide conditions and plant species.

\section{Conclusions}

This study was conducted to investigate the temporal variation in soil resistance to detachment by overland flow for topsoil incorporated with different plant litters in the Loess Plateau using undisturbed soil samples collected from four plots (a control plot and three litter incorporated plots) scoured under different flow shear stresses. The results showed that the incorporated plant litter was effective to enhance soil resistance to flowing water erosion. Compared to control, the mean $K_{r}$ 


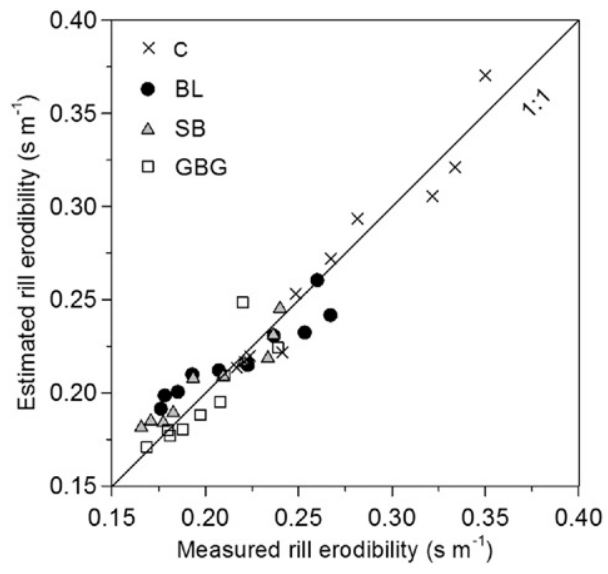

Fig. 7. The comparison between the measured and the estimated rill erodibilities.

of BL, SB, and GBG plots reduced by $24.3 \%, 33.5 \%$, and $34.8 \%$. The effects of litter incorporation in topsoil on rill erodibility were related to litter species. The temporal variations in rill erodibility of bare and litter incorporated soils were similar. Rill erodibility decreased over time as an exponential function. The relative rill erodibility of three plant litters increased over time as a power function, which indicated the decrease in the mechanical effects of incorporated litter on soil resistance to flowing water erosion. The critical shear strength increased over time as an exponential function. The seasonal changes in soil resistance to detachment by overland flow were closely related to soil consolidation, structural stability and litter decomposition. Rill erodibility could be well estimated by soil bulk density, water stable aggregate, and litter mass density $\left(r^{2}=0.92\right)$. The results of this study are helpful in understanding the mechanism of soil detachment process by overland flow for soils covered with vegetation in the Loess Plateau.

\section{Acknowledgements}

Financial assistance for this work was supplied by the National Natural Science Foundation of China (No. 41271287), the State Key Program of National Natural Science of China (No. 41530858), and the Hundred Talents Project of the Chinese Academy of Sciences. Members of the Ansai field station of Soil and Water Conservation, Chinese Academy of Sciences and Ministry of Water Recourses are kindly thanked for providing weather data.

\section{References}

Allison, F.E., 1968. Soil aggregation-some facts and fallacies as seen by a microbiologist. Soil Sci. 106, 136-143.

An, S.S., Cheng, Y., Huang, Y.M., Liu, D., 2013. Effects of revegetation on soil microbial biomass, enzyme activities, and nutrient cycling on the Loess Plateau in China. Restor. Ecol. 21, 600-607.

Barthes, B., Roose, E., 2002. Aggregate stability as an indicator of soil susceptibility to runoff and erosion; validation at several levels. Catena 47, 133-149.

Bhagat, R., Verma, T., 1991. Impact of rice straw management on soil physical properties and wheat yield. Soil Sci. 152, 108-115.

Black, A., 1973. Soil property changes associated with crop residue management in a wheat-fallow rotation. Soil Sci. Soc. Am. J. 37, 943-946.

Brown, L., Foster, G., Beasley, D., 1989. Rill erosion as affected by incorporated crop residue and seasonal consolidation. Trans. ASAE 32, 1967-1978.

Brown, L., West, L., Beasley, D., Foster, G., 1990. Rill erosion one year after incorporation of crop residue. Trans. ASAE 3, 1531-1540.

Chang, R., Fu, B., Liu, G., Liu, S., 2011. Soil carbon sequestration potential for "Grain for Green" project in Loess Plateau, China. Environ. Manag. 48 (6), 1158-1172.

Chen, L.D., Huang, Z.L., Gong, J., Fu, B.J., Huang, Y.L., 2007. The effect of land cover/vegetation on soil water dynamic in the hilly area of the loess plateau, China. Catena 70, 200-208.

Clark, D.A., Brown, S., Kicklighter, D.W., Chambers, J.Q., Thomlinson, J.R., Ni, J., Holland, E.A., 2001. Net primary production in tropical forests: an evaluation and synthesis of existing field data. Ecol. Appl. 11, 371-384.

Deng, L., Shangguan, Z.P., Sweeney, S., 2014. “Grain for Green” driven land use change and carbon sequestration on the Loess Plateau, China. Sci. Rep. 4, 7039.
Durán, Z.V.H., Francia Martínez, J., Martínez Raya, A., 2004. Impact of vegetative cover on runoff and soil erosion at hillslope scale in Lanjaron, Spain. Environmentalist 24, $39-48$.

Franti, T.G., 1987. Modeling the Mechanical Effects of Incorporated Residue on Rill Erosion (Ph.D. Thesis) Purdue University, Ann Arbor, MI, p. 48106.

Geddes, N., Dunkerley, D., 1999. The influence of organic litter on the erosive effects of raindrops and of gravity drops released from desert shrubs. Catena 36, 303-313.

Ghuman, B., Sur, H., 2001. Tillage and residue management effects on soil properties and yields of rainfed maize and wheat in a subhumid subtropical climate. Soil Tillage Res. 58, 1-10.

Kladivko, E.J., Unger, P., 1994. Residue Effects on Soil Physical Properties. Managing Agricultural Residues. Lewis Publishers, Boca Raton, FL, pp. 123-141.

Knapen, A., Poesen, J., De Baets, S., 2007a. Seasonal variations in soil erosion resistance during concentrated flow for a loess-derived soil under two contrasting tillage practices. Soil Tillage Res. 94, 425-440.

Knapen, A., Poesen, J., Govers, G., Gyssels, G., Nachtergaele, J., 2007b. Resistance of soils to concentrated flow erosion: a review. Earth-Sci. Rev. 80, 75-109.

Knapen, A., Poesen, J., De Baets, S., 2008. Rainfall-induced consolidation and sealing effects on soil erodibility during concentrated runoff for loess-derived topsoils. Earth Surf. Process. Landf. 33, 444-458.

Laossi, K.R., Ginot, A., Noguera, D.C., Blouin, M., Barot, S., 2010. Earthworm effects on plant growth do not necessarily decrease with soil fertility. Plant Soil 328, 109-118.

Léonard, J., Richard, G., 2004. Estimation of runoff critical shear stress for soil erosion from soil shear strength. Catena 57, 233-249.

Li, Z.W., Zhang, G.H., Geng, R., Wang, H., 2015a. Spatial heterogeneity of soil detachment capacity by overland flow at a hillslope with ephemeral gullies on the Loess Plateau. Geomorphology 248, 264-272.

Li, Z.W., Zhang, G.H., Geng, R., Wang, H., 2015b. Rill erodibility as influenced by soil and land use in a small watershed of the Loess Plateau, China. Biosyst. Eng. 129, 248-257.

Li, Z.W., Zhang, G.H., Geng, R., Wang, H., Zhang, X., 2015c. Land use impacts on soil detachment capacity by overland flow in the Loess Plateau, China. Catena 124, 9-17.

Luk, S., Merz, W., 1992. Use of the salt tracing technique to determine the velocity of overland flow. Soil Technol. 5, 289-301.

Ma, Y., Filley, T.R., Szlavecz, K., McCormick, M.K., 2014. Controls on wood and leaf litter incorporation into soil fractions in forests at different successional stages. Soil Biol. Biochem. 69, 212-222.

Mamo, M., Bubenzer, G., 2001. Detachment rate, soil erodibility, and soil strength as influenced by living plant roots. Part II: field study. Trans. ASAE 44, 1175-1181.

Mandal, K.G., Misra, A.K., Hati, K.M., Bandyopadhyay, K.K., Ghosh, P.K., Mohanty, M., 2004. Rice residue-management options and effects on soil properties and crop productivity. J. Food Agric. Environ. 2, 224-231.

Mapa, R.B., Green, R., Santo, L., 1986. Temporal variability of soil hydraulic properties with wetting and drying subsequent to tillage. Soil Sci. Soc. Am. J. 50, 1133-1138.

Morachan, Y., Moldenhauer, W., Larson, W., 1972. Effects of increasing amounts of organic residues on continuous corn: I. Yields and soil physical properties. Agron. J. 64, 199-203.

Nearing, M.A., Foster, G.R., Lane, L.J., Finkner, S.C., 1989. A process-based soil erosion model for USDA-water erosion prediction project technology. Trans. ASAE 32, 1587-1593.

Nearing, M., Bradford, J., Parker, S., 1991. Soil detachment by shallow flow at low slopes. Soil Sci. Soc. Am. J. 55, 339-344.

Olson, J.S., 1963. Energy storage and the balance of producers and decomposers in ecological systems. Ecology 44, 322-331.

Pannkuk, C.D., Robichaud, P.R., 2003. Effectiveness of needle cast at reducing erosion after forest fires. Water Resour. Res. 39, 1333.

Tsukamoto, J., 1991. Downhill movement of litter and its implication for ecological studies in three types of forest in Japan. Ecol. Res. 6, 333-345.

Van Liew, M., Saxton, K., 1983. Slope steepness and incorporated residue effects on rill erosion. Trans. ASAE 26, 1738-1743.

Wang, Y., Shao, M.A., Liu, Z., 2010. Large-scale spatial variability of dried soil layers and related factors across the entire Loess Plateau of China. Geoderma 159, 99-108.

Wang, B., Zhang, G.H., Zhang, X., Li, Z.W., Su, Z.L., Yi, T., Shi, Y.Y., 2014. Effects of near soil surface characteristics on soil detachment by overland flow in a natural succession grassland. Soil Sci. Soc. Am. J. 78, 589-597.

Wilson, G.V., McGregor, K.C., Boykin, D., 2008. Residue impacts on runoff and soil erosion for different corn plant populations. Soil Tillage Res. 99, 300-307.

Yu, Y.C., Zhang, G.H., Geng, R., Li, Z.W., 2014a. Temporal variation in soil rill erodibility to concentrated flow detachment under four typical croplands in the Loess Plateau of China. J. Soil Water Conserv. 69, 352-363.

Yu, Y.C., Zhang, G.H., Geng, R., Sun, L., 2014b. Temporal variation in soil detachment capacity by overland flow under four typical crops in the Loess Plateau of China. Biosyst. Eng. 122, 139-148.

Zeleke, T., Grevers, M., Si, B., Mermut, A., Beyene, S., 2004. Effect of residue incorporation on physical properties of the surface soil in the South Central Rift Valley of Ethiopia. Soil Tillage Res. 77, 35-46.

Zhang, G.H., Liu, B.Y., Liu, G.B., He, X.W., Nearing, M., 2003. Detachment of undisturbed soil by shallow flow. Soil Sci. Soc. Am. J. 67, 713-719.

Zhang, G.H., Tang, K.M., Zhang, X.C., 2009. Temporal variation in soil detachment under different land uses in the Loess Plateau of China. Earth Surf. Process. Landf. 34, 1302-1309.

Zhang, G.H., Tang, K.M., Sun, Z.L., Zhang, X.C., 2014. Temporal variability in rill erodibility for two types of grasslands. Soil Res. 52, 781-788. 